\title{
Pulmonary Metastasis of Basal Cell Carcinoma
}

\author{
Sang-Hee Seo, M.D., Woo-Haing Shim, M.D., Dong-Hoon Shin, M.D. ${ }^{1}$, Yun-Seong Kim, M.D. ${ }^{2}$, \\ Hyun-Woo Sung, M.D. ${ }^{3}$
}

Department of Dermatology and Medical Research Institute, Departments of ${ }^{1}$ Pathology and ${ }^{2}$ Internal Medicine, Yangsan Pusan National University Hospital, ${ }^{3}$ Department of Orthopedics, Dong-A University Medical Center, Busan, Korea

\begin{abstract}
Although basal cell carcinoma is the most common skin cancer, it rarely metastasizes. Metastatic basal cell carcinoma may, therefore, initially elude diagnosis and management. We describe the case of a patient with a metastatic basal cell carcinoma present in the lungs. The differential diagnosis of suspected metastatic lesions should include metastases from a cutaneous basal cell carcinoma, in addition to those from more commonly metastasizing carcinomas, especially in patients with a history of a large basal cell carcinoma that has involved the head and neck regions, and was refractory to treatment. (Ann Dermatol 23(2) $213 \sim 216,2011$ )
\end{abstract}

\section{-Keywords-}

Basal cell carcinoma, Metastatic basal cell carcinoma, Pulmonary metastasis

\section{INTRODUCTION}

Basal cell carcinoma (BCC) is the most common skin tumor, and is characterized by invasive growth and local tissue destruction. Despite the high incidence of BCC, metastasis of this tumor is rare, with rates ranging from $0.0028 \%$ to $0.55 \%$ of all BCC cases ${ }^{1}$. Since metastatic basal cell carcinoma (MBCC) was first reported in 1984 by Min et al. ${ }^{2}$, there have been only 2 more cases reported in the Korean literature ${ }^{3,4}$. Due to the rarity of MBCC, at initial presentation this tumor may be mistaken to have

Received April 12, 2010, Revised May 22, 2010, Accepted for publication May 22, 2010

*This study was supported by a 2011 research grant from Yansan Pusan National University Hospital.

Corresponding author: Yun-Seong Kim, M.D., Department of Internal Medicine, Yangsan Pusan National University Hospital, Beomeo-ri, Mulgeum-eup, Yangsan 626-770, Korea. Tel: 82-55-360-1674, Fax: 82-55-360-1679, E-mail: soesh97@lycos.co.kr originated from other metastasis-prone tumors. We present a case of MBCC presenting with 2 isolated lung masses that resembled lung cancer or tuberculoma, but were subsequently diagnosed as MBCC on the basis of histopathological findings, and history of facial BCC 17 years ago.

\section{CASE REPORT}

A 50-year-old man visited our respiratory clinic for further evaluation of 2 pulmonary nodules. Computed tomography revealed a $2 \mathrm{~cm}$ wide nodule in the right upper lobe (Fig. 1) and a $2.5 \mathrm{~cm}$ wide nodule in the left upper lobe of the lung. Pathological examination of fine-needle aspiration biopsy specimens of the pulmonary nodules revealed findings suggestive of BCC. The patient reported that he had a BCC on the left cheek excised 17 years ago,

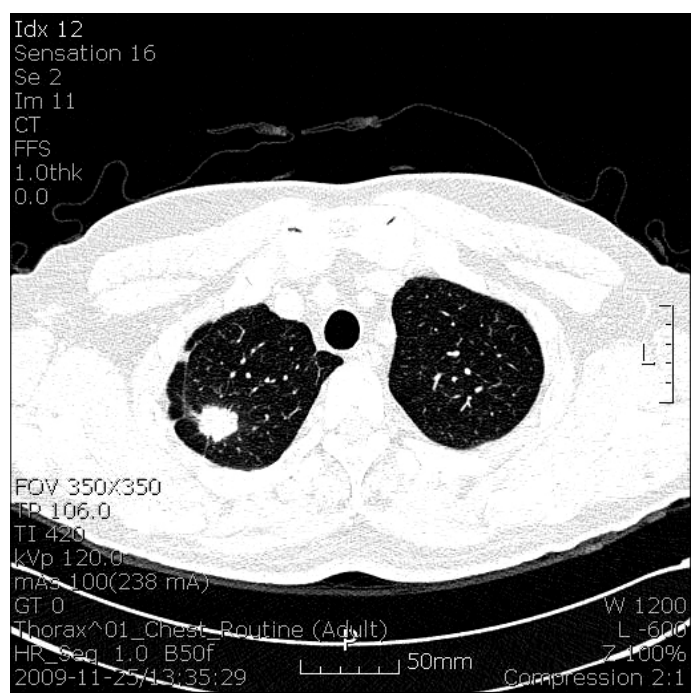

Fig. 1. Computed tomography of the chest showing a wellenhanced pulmonary nodule on right upper lobe of lung. 
in a plastic surgery clinic. Local recurrences occurred at the same site 5, 9, and 10 years after the excision, eventually leading to invasion of the left maxillary bone, after which he underwent repeated tumor excisions and eventually, removal of the left maxillary bone. However, no pulmonary invasion was observed on computed tomography at the time of the last excision. No evidence of tumor recurrence was detected in the 7 years between
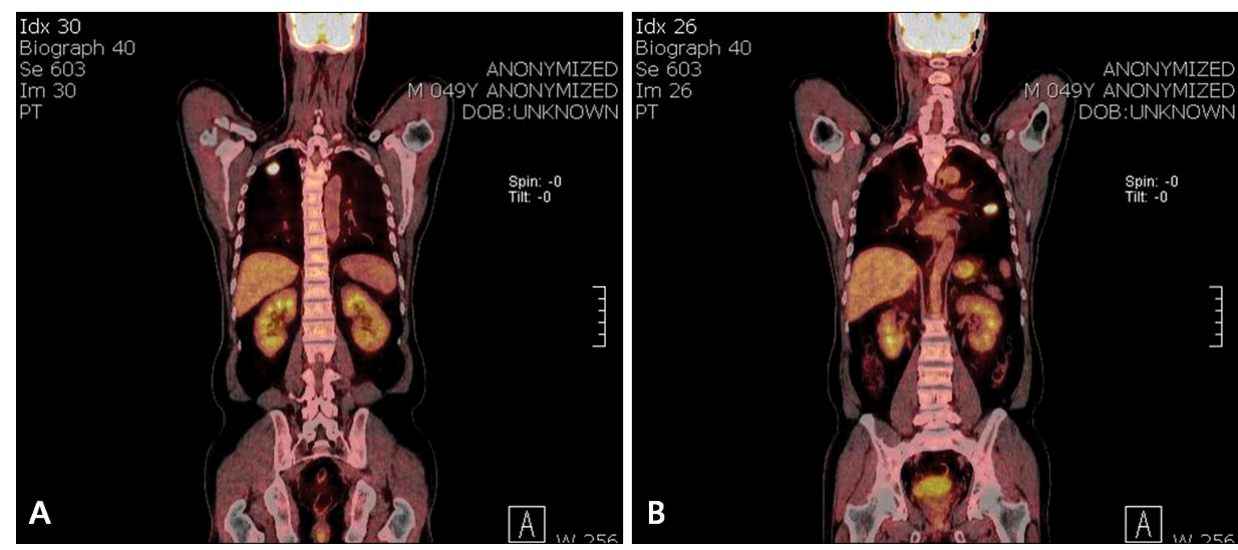

Fig. 2. Positron emission tomography scan showed increased uptake on the right upper lung mass (A) and left lung mass (B).
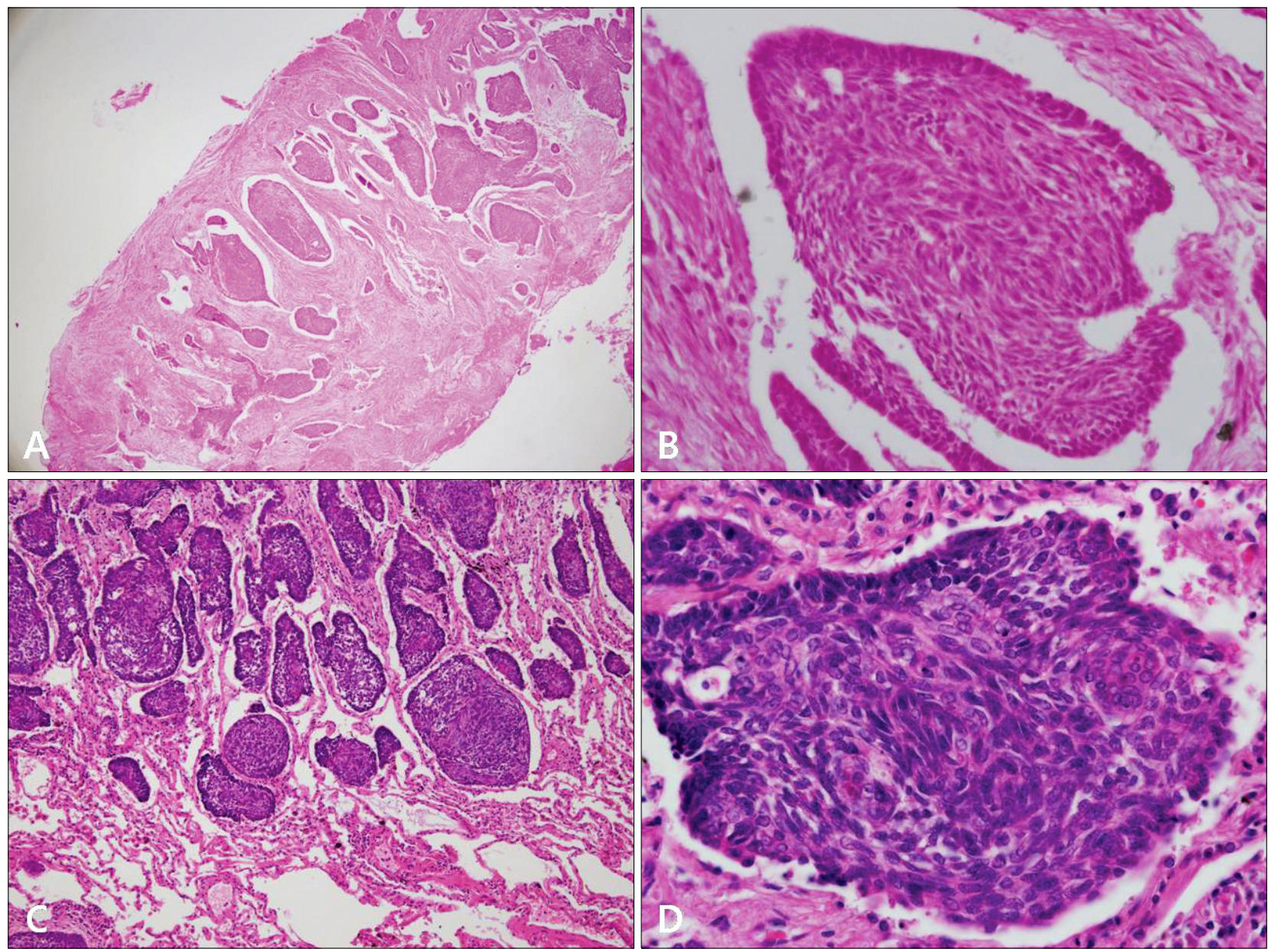

Fig. 3. (A) Pathological examination of the excised pulmonary nodule demonstrated irregularly shaped tumor masses and retraction of the stroma around the tumor islands $(\mathrm{H} \& \mathrm{E}, \times 40)$. (B) The tumor from the lung was composed of basaloid cell nests with peripheral palisading $(\mathrm{H} \& \mathrm{E}, \times 400)$. (C) The patient's left maxilla BCC excised 10 years earlier showed similar histopathology with pulmonary MBCC $(\mathrm{H} \& \mathrm{E}, \times 40)$. (D) The tumor cells from left maxilla are basaloid cells showing peripheral palisading $(\mathrm{H} \& \mathrm{E}, \times 400)$. 
the last excision and the current pulmonary presentation. He had neither a family history of skin cancer nor any personal history suggestive of basal cell nevus syndrome. Positron-emission tomography scan showed an increased uptake in both pulmonary nodules with a maximum standard uptake value of 12.7 in the right-upper lung mass and 8.8 in the lingular segment mass of the left lung (Fig. 2). No abnormal activity was detected outside the lungs. Thereafter, he underwent a total excision of the pulmonary nodules and dissection of the lymph node. Pathological examination of the excised pulmonary nodule revealed irregularly shaped aggregates, nests of basaloid cells with peripheral palisading and retraction of the stroma around the tumor islands, creating microscopically visible clefts (Fig. 3A, B). A negative reaction for neuron-specific enolase CK-20 helped to differentiate it from Merkel cell carcinoma. These findings were very similar to the histological features of the patient's left maxillary BCC which was excised 10 years ago (Fig. 3C, D). The patient was administered postoperative chemotherapy with 5-fluorouracil (FU) and cisplatin.

\section{DISCUSSION}

MBCC is defined as a tumor that metastasizes from primary cutaneous BCC lesions to distant noncontiguous sites and exhibits similar histological characteristics to those of the primary $\mathrm{BCC}^{5}$. The male-female ratio of the incidence of BCC metastasis is $2: 1^{6}$. The median age at tumor onset is 45 years and the median interval between tumor onset and the presenting signs of metastasis is 9 years $^{6}$. Most MBCCs (70\%) originate from a primary BCC in the head and neck region ${ }^{6}$. MBCC is most often manifested as a dissemination to the regional lymph nodes $(60 \%)$ or hematogenous spread to the lung $(42 \%)$, bone $(20 \%)$, or skin $(10 \%)$, with symptoms such as lymphadenopathy, ulceration, anemia, bone pain, and muscle weakness depending on the site of metastasis ${ }^{6-8}$. The lung, although a distant site, is most often involved in MBCC, and almost 50 such cases have been reported to date ${ }^{9-11}$. Most MBCCs involving the lungs are disseminated multiple small nodules that originate because of hematogenous spread. In the current case, MBCC presented as 2 isolated nodules that resemble lung cancer or tuberculoma. Known risk factors for MBCC include large primary tumors $(>2 \mathrm{~cm})$, location in the head and neck regions, multiple tumor recurrences, prior radiation therapy, multiple primary tumors, large tumor depth, invasion of perineural space and blood vessels, fair skin, and male gender ${ }^{10}$. Several other risk factors have been proposed such as specific subtypes of primary BCC, a metatypical pattern, and immunosuppression in affected patients ${ }^{10}$. In our patient, the primary BCC was located in the head region, recurred despite repeated excisions, and eventually invaded the left maxillary bone. In addition, owing to the number of MBCC cases, prospective studies cannot be conducted on the effectiveness of various treatment modalities for this tumor. Therapeutic options vary depending on the location and extent of $\mathrm{MBCC}$, but generally consist of surgery for local metastasis, and a combination of surgery, chemotherapy, and radiation therapy for distant metastasis. If complete surgical excision is not possible, chemotherapy is preferred, with cisplatinum being the most effective agent ${ }^{12}$. Radiation therapy may be administered postoperatively or concomitantly with chemotherapy. However, despite the limited data regarding the role of radiation therapy in MBCC treatment, the latter option is preferred for improved local control and organ preservation. The prognosis for MBCC is generally poor because of an inconsistent response to chemotherapy or surgery $^{13}$. von Domarus and Stevens ${ }^{6}$ reported that the median survival time after initial metastasis was 8 months, although survival times of several years have also been reported ${ }^{9}$. The above findings suggest that this rare complication of a common malignancy has a variable clinical course.

In conclusion, we reported a case of MBCC presenting as 2 isolated pulmonary nodules that resembled lung cancer or tuberculoma. Although MBCC is rare, awareness regarding this condition is necessary, and it should be included in the differential diagnosis of any patient with a history of a large BCC in the head and neck region and multiple tumor recurrences despite treatment.

\section{REFERENCES}

1. Oram Y, Orengo I, Alford E, Green LK, Rosen T, Netscher DT. Basal cell carcinoma of the scalp resulting in spine metastasis in a black patient. J Am Acad Dermatol 1994; 31:916-920.

2. Min BG, Kim YK, Choi KC. A case of metastatic basal cell carcinoma. Korean J Dermatol 1984;22:79-82.

3. Jang YS, Kim KJ, Lee ES, Lee CJ. A case of multiple basal cell carcinoma. Korean J Dermatol 1988;26:768-773.

4. Chun $\mathrm{Cl}$, Lee SC, Won $\mathrm{YH}$, Chun IK. A case of metastatic basal cell carcinoma occured after radiation therapy. Korean J Dermatol 1996;34:810-814.

5. Lattes R, Kessler RW. Metastasizing basal-cell epithelioma of the skin; report of two cases. Cancer 1951;4:866-878.

6. von Domarus H, Stevens PJ. Metastatic basal cell carcinoma. Report of five cases and review of 170 cases in the literature. J Am Acad Dermatol 1984;10:1043-1060.

7. Snow SN, Sahl W, Lo JS, Mohs FE, Warner T, Dekkinga JA, et al. Metastatic basal cell carcinoma. Report of five cases. 
Cancer 1994;73:328-335.

8. Berlin JM, Warner MR, Bailin PL. Metastatic basal cell carcinoma presenting as unilateral axillary lymphadenopathy: report of a case and review of the literature. Dermatol Surg 2002;28:1082-1084.

9. Pena T, LoRusso PM, Ruckdeschel JC, Goncalves P, Soubani AO. Pulmonary metastasis of basal cell carcinoma: a rare manifestation of a common disease with variable clinical course. J Thorac Oncol 2009;4:1026-1027.

10. Boswell JS, Flam MS, Tashjian DN, Tschang TP. Basal cell carcinoma metastatic to cervical lymph nodes and lungs.
Dermatol Online J 2006;12:9.

11. Ting PT, Kasper R, Arlette JP. Metastatic basal cell carcinoma: report of two cases and literature review. J Cutan Med Surg 2005;9:10-15.

12. Pfeiffer $P$, Hansen $O$, Rose C. Systemic cytotoxic therapy of basal cell carcinoma. A review of the literature. Eur J Cancer 1990;26:73-77.

13. Bason MM, Grant-Kels JM, Govil M. Metastatic basal cell carcinoma: response to chemotherapy. J Am Acad Dermatol 1990;22:905-908. 